06

\title{
Оптимальные условия легирования никелем для повышения эффективности кремниевых фотоэлементов
}

\author{
(C) М.К. Бахадырханов, ${ }^{1}$ 3.T. Кенжаев ${ }^{2}$ \\ ${ }^{1}$ Ташкентский государственный технический университет, \\ 100095 Ташкент, Узбекистан \\ ${ }^{2}$ Каракалпакский государственный университет, \\ 230112 Нукус, Узбекистан \\ e-mail: zoir1991@bk.ru
}

Поступило в Редакцию 2 декабря 2020 г.

В окончательной редакции 2 декабря 2020 г.

Принято к публикации 8 декабря 2020 г.

Исследована стабильность обогащенного никелем поверхностного слоя кремния при термообработках. При термообработках ниже $900^{\circ} \mathrm{C}$ обогащенный никелем слой сохраняется. Установлено, что легирование кремниевого фотоэлемента никелем приводит к улучшению эффективности независимо от глубины залегания $p-n$-перехода. Оптимальные условия диффузии никеля в кремний $T=800-850^{\circ} \mathrm{C}, t=30 \mathrm{~min}$. Наблюдался рост тока короткого замыкания фотоэлементов, легированных никелем, во всей исследованной области спектра. Показано, что легирование никелем до формирования $p-n$-перехода фотоэлемента является более эффективным и технологичным. Улучшение параметров фотоэлемента при легировании никелем в основным связано с свойствами поверхностного слоя.

Ключевые слова: кремний, фотоэлемент, легирование никелем, диффузия, термоотжиг, кластер, поверхностный слой.

DOI: $10.21883 / J T F .2021 .06 .50868 .332-20$

\section{Введение}

В работах [1,2] было показано, что формирование обогащенного никелем слоя в приповерхностной области кремниевых фотоэлементов (ФЭ) с глубоким $p-n$-переходом приводит к улучшению их параметров. В этих работах легирование кремния никелем проводилось при достаточно высокой температуре $\left(T=1200^{\circ} \mathrm{C}\right)$, и после формирования $p-n$-перехода может ухудшать эффективность фотоэлемента из-за разгонки фосфора.

Целью настоящей работы являлось изучение особенностей влияния легирования никелем, в том числе приповерхностного обогащенного никелем слоя на параметры фотоэлемента и определение оптимальных технологических условий легирования, пригодных для использования в промышленном производстве фотоэлементов.

При диффузионном легировании никель имеет достаточно высокую объемную растворимость $\left(n \sim 10^{18} \mathrm{~cm}^{-3}\right)$. В то же время в приповерхностной области $(d=2-3 \mu \mathrm{m})$ его концентрация может достигать $n_{S} \sim 10^{20}-10^{21} \mathrm{~cm}^{-3}[3,4]$.

Основная часть растворенных атомов - 99.999\%, а в приповерхностной области еще больше, находятся в электронейтральном состоянии в междоузлиях, и при определенных условиях термообработки могут формировать кластеры [5].

Указанные выше кластеры, расположенные в дефектных приповерхностных слоях, на лицевой и тыльной сто- ронах ФЭ могут действовать как эффективные центры геттерирования для рекомбинационных неконтролируемых примесных атомов и кислорода [6,7]. Кроме того, они могут за счет своей „металлической“ проводимости эффективно уменьшать поверхностное сопротивление лицевого $n$-слоя $Ф Э$, что приводит к уменьшению последовательного сопротивления.

В связи с этим были поставлены следующие задачи.

1. Исследовать стабильность обогащенного никелем слоя кремния.

2. Определить оптимальную температуру легирования никелем.

3. Оценить эффективность легирования никелем для фотоэлементов с различной глубиной $p-n$-перехода.

4. Исследовать возможность легирования никелем до формирования $p-n$-перехода ФЭ.

5. Результаты таких исследований могут быть непосредственно применены в технологии производства кремниевых ФЭ.

\section{1. Исследование стабильности обогащенного никелем слоя кремния}

Для проверки стабильности приповерхностного обогащенного никелем слоя, образующегося в условиях промышленной технологии ФЭ, была проведена диффузия 


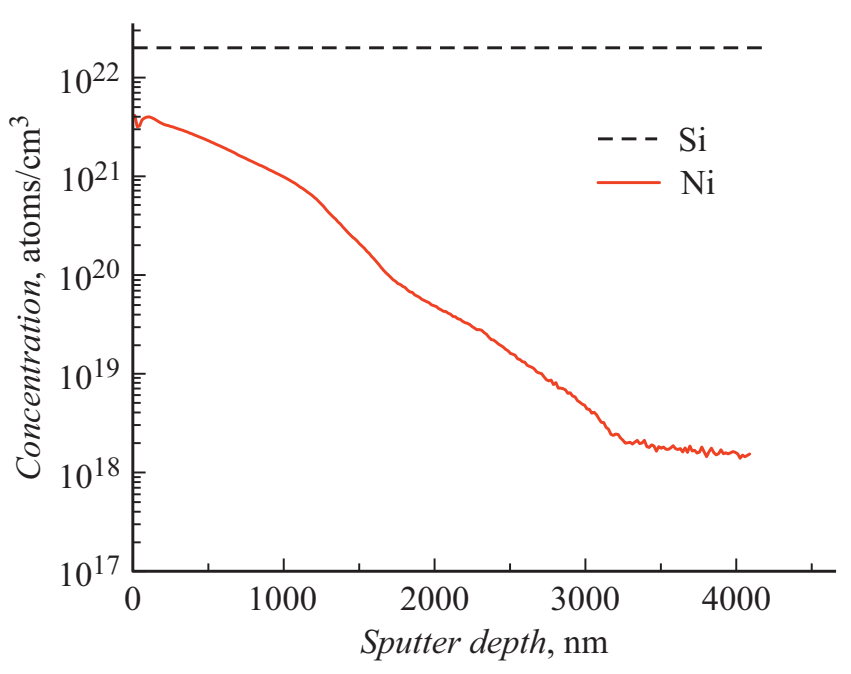

Рис. 1. Распределение атомов никеля в поверхностном слое кремния.

никеля из металлической пленки в кремниевые пластины $p$-типа с удельным сопротивлением $0.5 \Omega \cdot \mathrm{cm}$, толщиной $380 \mu \mathrm{m}$ и диаметром $76 \mathrm{~mm}$ при $T_{d i f f}=1200^{\circ} \mathrm{C}$, в течение $30 \mathrm{~min}$. На рис. 1 показано распределение атомов никеля в приповерхностном слое кремния, полученное на CAMECA IMS-6f Magnetic Sector SIMS.

Как видно из рисунка, поверхностная концентрация никеля $n_{S} \sim 4 \cdot 10^{21} \mathrm{~cm}^{-3}$, а толщина обогащенного слоя $d \sim 3-3.2 \mu \mathrm{m}$. Эксперимент показал, что при последующих термообработках с температурой ниже $900^{\circ} \mathrm{C}$ обогащенный слой сохраняется. Это видимо обусловливается тем, что дефекты приповерхностного слоя являются центрами преципитации атомов никеля. Также экспериментально установлено, что максимальная концентрация никеля в приповерхностном обогащенном слое слабо зависит от температуры диффузии.

Измерения поверхностного сопротивления четырехзондовым методом, выполненные при послойном шлифовании образцов (по $10 \mu \mathrm{m})$, показали незначительное влияние никеля на удельное сопротивление объема кремния, подтверждая результаты работ [8,9].

\section{2. Определение оптимальной температуры легирования никелем}

Исходные $p-n$-структуры $Ф Э$ создавались диффузией фосфора в кремниевые пластины $p$-типа с удельным сопротивлением $0.5 \Omega \mathrm{cm}$ при $T_{d i f f}=1000^{\circ} \mathrm{C}$ в течение $t=0.5 \mathrm{~h}$. Далее полученная структура разрезалась на отдельные образцы размером $1 \times 1 \mathrm{~cm}$. Параметры всех полученных фотоэлементов были практически одинаковы. На поверхность диффузионного слоя $n$-типа (на лицевую сторону фотоэлемента) в вакууме напылялся слой чистого никеля толщиной $1 \mu \mathrm{m}$. С учетом коэффициента диффузии $\mathrm{Ni}$ в кремний было рассчитано оптимальное время диффузии для каждой температуры $[3,10,11]$. Диффузия никеля проводилась в интервале температур $T_{d i f f}=700-1300^{\circ} \mathrm{C}$, с шагом $50^{\circ} \mathrm{C}$. Все образцы проходили дополнительный термоотжиг при $T_{a n n}=750-800^{\circ} \mathrm{C}$ в течение $t=30 \mathrm{~min}$ после диффузии никеля с целью активации процесса геттерирования [12-14] неконтролируемых рекомбинационных примесей.

Для контроля изготавливались образцы ФЭ, у которых этапы, связанные с диффузией никеля и дополнительным термоотжигом, не проводились. Полученные контрольные образцы примерно соответствуют конструкции типового промышленного ФЭ без просветляющего покрытия.

После каждого технологического этапа проводилась очистка поверхности и химическая обработка, чтобы снять остатки никеля и оксид кремния с поверхности. Затем напылением никеля создавались омические контакты. На тыльной стороне напылялся сплошной контакт, а на лицевой - через трафарет. Просветляющее покрытие на поверхности элементов отсутствовало. После получения контактов для всех образцов при одинаковых условиях были измерены ВАХ фотоэлементов и определены параметры - напряжение холостого хода $V_{o c}$ и плотность тока короткого замыкания $J_{s c}$, максимальная отдаваемая мощность $P_{\max }$ и коэффициент заполнения BAX $\xi\left(\xi=P_{\max } / J_{s c} V_{o c}\right)$. В табл. 1 представлены основные параметры полученных фотоэлементов.

Как видно из табл. 1, с понижением температуры диффузии никеля происходит практически монотонное улучшение параметров $J_{s c}$ и $V_{o c}$. Следует отметить, что значение $J_{s c}$ увеличилось больше чем на $56 \%$, a $V_{o c}$ на 9.1\% (при температуре диффузии никеля $\left.T_{d i f f}=800^{\circ} \mathrm{C}\right)$ по отношению к ФЭ, в которых диффузия никеля проводилась при $1300^{\circ} \mathrm{C}$. В то же время при сравнении с контролем $\left(J_{s c}=32 \mathrm{~mA} / \mathrm{cm}^{2}, V_{o c}=590 \mathrm{mV}\right.$, $\left.\xi=0.64, P_{\max }=12.08 \mathrm{~mW} / \mathrm{cm}^{2}\right)$, параметры $Ф Э$, легированных никелем, начинают улучшаться при температуре диффузии никеля $T_{\operatorname{diff}} \leq 1000^{\circ} \mathrm{C}$.

Диффузия никеля, проведенная при более низких температурах $-T_{d i f f}=750-700^{\circ} \mathrm{C}$, приводила к незначительному ухудшению параметров фотоэлементов (в отношении образцов, полученных при $T_{d i f f}=800^{\circ} \mathrm{C}$ ). Это может быть связано с уменьшением толщины обогащенной никелем области, а также с понижением концентрации атомов никеля при таких температурах диффузии.

Таким образом, на основе этих результатов можно утверждать, что оптимальная температура диффузии никеля составляет $T_{d i f f}=800-850^{\circ} \mathrm{C}$. Низкая температура диффузии (ниже $900^{\circ} \mathrm{C}$ ) существенно ослабляет процесс разгонки примеси фосфора в $p-n$-переходе, и его глубина почти не меняется. Это особенно важно для мелких $p-n$-переходов. 
Таблица 1. Средние значения параметров ФЭ, полученных при разных температурах диффузии никеля

\begin{tabular}{c|c|c|c|c|c|c|c|c|c|c|c}
\hline$T_{\text {diff }},{ }^{\circ} \mathrm{C}$ & 1300 & 1250 & 1200 & 1100 & 1050 & 1000 & 950 & 900 & 850 & 800 & 750 \\
\hline$t, \mathrm{~min}$ & 3 & 3 & 3 & 5 & 7 & 10 & 15 & 20 & 30 & 30 & 60 \\
\hline$T_{a n n},{ }^{\circ} \mathrm{C}$ & 800 & 800 & 800 & 800 & 800 & 800 & 800 & 800 & 750 & 750 & 700 \\
\hline$x_{p-n}, \mu \mathrm{m}$ & 3.51 & 2.35 & 1.56 & 0.87 & 0.70 & 0.60 & 0.56 & 0.54 & 0.53 & 0.53 & 0.53 \\
\hline$J_{s c}, \mathrm{~mA} / \mathrm{cm}^{2}$ & 24 & 26 & 28 & 29 & 30 & 32.8 & 34.2 & 34.8 & 36.5 & 37.5 & 36 \\
\hline$V_{o c}, \mathrm{mV}$ & 550 & 560 & 570 & 575 & 580 & 585 & 590 & 595 & 600 & 600 & 590 \\
\hline$\xi$ & 0.71 & 0.708 & 0.705 & 0.70 & 0.698 & 0.692 & 0.689 & 0.686 & 0.68 & 0.68 & 0.68 \\
\hline$P_{\max }, \mathrm{mW} / \mathrm{cm}^{2}$ & 9.37 & 10.31 & 11.25 & 11.67 & 12.14 & 13.28 & 13.90 & 14.20 & 14.89 & 15.30 & 14.44
\end{tabular}

Примечание. $T_{d i f f}-$ температура диффузии никеля, $t-$ время диффузии, $T_{a n n}-$ температура дополнительного термоожига, $x_{p-n}-$ расчетная глубина $p-n$-перехода.

Таблица 2. Средние значения параметров ФЭ, не легированных никелем (контроль) и легированных никелем с разными глубинами залегания $p-n$-перехода

\begin{tabular}{|c|c|c|c|c|c|c|c|c|c|}
\hline \multicolumn{2}{|c|}{$\begin{array}{c}\text { Глубина залегания } \\
p-n \text {-перехода, } \mu \mathrm{m}\end{array}$} & 28 & 15 & 9 & 6 & 3 & 2 & 1 & $0.5-0.75$ \\
\hline I группа & $\begin{array}{c}J_{s c}, \mathrm{~mA} / \mathrm{cm}^{2} \\
V_{o c}, \mathrm{mV} \\
\xi \\
P_{1 \max }, \mathrm{mW} / \mathrm{cm}^{2}\end{array}$ & $\begin{array}{c}7.5 \\
500 \\
0.68 \\
2.55\end{array}$ & $\begin{array}{c}14.7 \\
530 \\
0.667 \\
5.196\end{array}$ & $\begin{array}{c}19 \\
552 \\
0.662 \\
6.943\end{array}$ & $\begin{array}{c}21.8 \\
560 \\
0.659 \\
8.045\end{array}$ & $\begin{array}{c}25.2 \\
570 \\
0.657 \\
9.437\end{array}$ & $\begin{array}{c}27 \\
575 \\
0.652 \\
10.122\end{array}$ & $\begin{array}{c}30 \\
585 \\
0.645 \\
11.320\end{array}$ & $\begin{array}{c}32 \\
590 \\
0.640 \\
12.083\end{array}$ \\
\hline II группа & $\begin{array}{c}J_{s c}, \mathrm{~mA} / \mathrm{cm}^{2} \\
V_{o c}, \mathrm{mV} \\
\xi \\
P_{2 \max }, \mathrm{mW} / \mathrm{cm}^{2}\end{array}$ & $\begin{array}{l}12.5 \\
540 \\
0.72 \\
4.86\end{array}$ & $\begin{array}{c}21 \\
560 \\
0.71 \\
8.408\end{array}$ & $\begin{array}{c}25.3 \\
575 \\
0.705 \\
10.256\end{array}$ & $\begin{array}{c}28 \\
580 \\
0.7 \\
11.368\end{array}$ & $\begin{array}{c}31.3 \\
585 \\
0.697 \\
12.762\end{array}$ & $\begin{array}{c}33 \\
590 \\
0.692 \\
13.473\end{array}$ & $\begin{array}{c}36 \\
595 \\
0.684 \\
14.651\end{array}$ & $\begin{array}{c}37.5 \\
600 \\
0.680 \\
15.30\end{array}$ \\
\hline$\left(P_{2 \max }\right.$ & ax $) / P_{1 \max }, \%$ & 90.59 & 61.58 & 47.716 & 41.304 & 35.236 & 33.105 & 29.43 & 26.622 \\
\hline
\end{tabular}

\section{3. Эффективность легирования никелем для ФЭ с различной глубиной $p-n$-перехода}

Управляя температурой и временем диффузии фосфора $[10,11,15]$ в интервале $T_{d i f f}=1000-1280^{\circ} \mathrm{C}$ и $t=0.5-5 \mathrm{~h}$ в кремнии $p$-типа с $0.5 \Omega \mathrm{cm}$, были изготовлены контрольные фотоэлементы с различной глубиной $p-n$-перехода - от 28 до $0.5-0.75 \mu \mathrm{m}$. В табл. 2 представлены основные параметры таких фотоэлементов $\mathrm{Si}\langle\mathrm{P}\rangle$ (I группа - контроль), не легированных никелем, без просветляющего покрытия. Никелевые омические контакты создавались по вышеприведенной технологии. Как видно из таблицы, с уменьшением глубины $p-n$-перехода основные параметры фотоэлемента увеличиваются и максимальные их значения наблюдаются в фотоэлементах с $0.5-0.75 \mu \mathrm{m}$. Эти данные хорошо согласуются с теорией и экспериментом [16-18].

У типа (на лицевую сторону фотоэлемента) в вакууме напылялся слой чистого никеля толщиной $1 \mu \mathrm{m}$ и подвергался диффузии при $T_{d i f f}=800^{\circ} \mathrm{C}$ в течение $t=30 \mathrm{~min}$. После диффузии проводился дополнительный термоот- жиг при $T_{a n n}=750^{\circ} \mathrm{C}$, длительностью $t=30 \mathrm{~min}$. После отжига остаток никеля на поверхности удалялся травлением в $\mathrm{HCl}$, а затем в $\mathrm{HF}$ до получения чистой поверхности. Никелевые омические контакты изготавливались аналогично контролю (I группа). Параметры $\Phi \ni$ измерялись в тех же условиях, что и контрольных образцов. В табл. 2 представлены основные параметры фотоэлементов II группы (также без просветляющего покрытия). В последней строке приведено относительное изменение максимальной мощности по сравнению с контролем.

Как видно из табл. 2, легирование никелем приводит к улучшению параметров ФЭ не зависимо от глубины залегания $p-n$-перехода. Положительное влияние никеля сохраняется на достаточно высоком уровне в ФЭ с малой глубиной $p-n$-перехода. Например, в ФЭ с глубиной $p-n$-перехода $0.5-0.75 \mu \mathrm{m}$, легированных никелем, значение $J_{s c}$ увеличивается на $17.2 \%, V_{o c}-$ на $2 \%$, коэффициент заполнения $\xi-$ на $6.25 \%$ относительно контрольных фотоэлементов.

Полученные результаты мы связываем с влиянием обогащенного никелем слоя в приповерхностной области ФЭ. Обогащенный никелем слой может являться гет- 

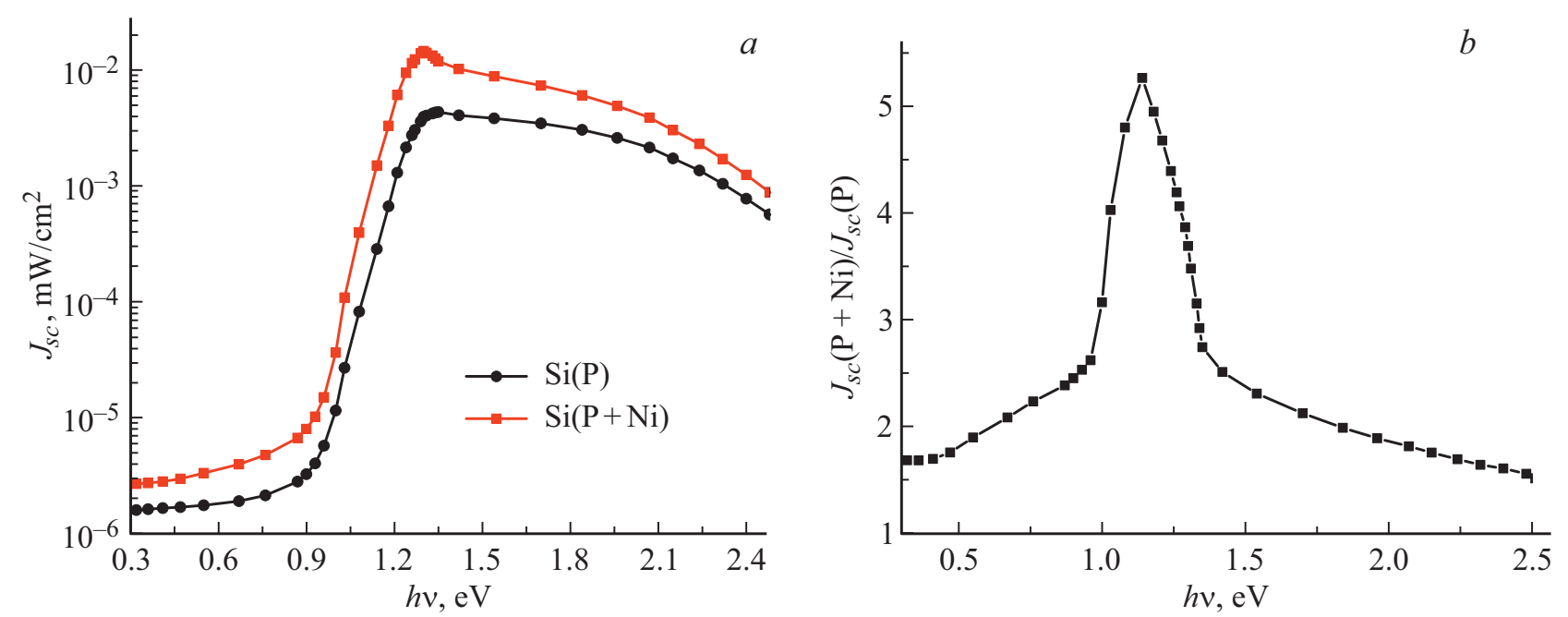

Рис. 2. Спектральные зависимости фотоэлементов: $a-J_{s c}, b-\left(J_{s c(\mathrm{Ni}+\mathrm{P})}-J_{s c(\mathrm{P})}\right) / J_{s c(\mathrm{P})}$.

терирующим, а также может уменьшать поверхностное сопротивление тонкого лицевого $n$-слоя $Ф Э$, увеличивая коэффициент заполнения ВАХ.

\section{4. Спектральные зависимости тока короткого замыкания ФЭ}

На рис. 2, $a$ представлена спектральная зависимость $J_{s c}(h v)$ ФЭ $\mathrm{Si}\langle\mathrm{P}+\mathrm{Ni}\rangle$, легированных никелем при температуре $T_{d i f f}=850^{\circ} \mathrm{C}$, и контрольных $Ф Э \mathrm{Si}\langle\mathrm{P}\rangle$, не легированных никелем, измеренных при одинаковых условиях. Как видно из рисунка, при этом наблюдается существенный рост величины $J_{s c}$, практически во всей исследуемой области спектра. На рис. 2, $b$ представлена спектральная зависимость относительного изменения величины $J_{s c}$ фотоэлемента, легированного никелем, к току $Ф Э$, не легированного никелем.

Как видно из рисунка, улучшение чувствительности фотоэлементов, легированных никелем относительно контрольных, начинается в инфракрасной области спектра и монотонно увеличивается до $\lambda=1.24 \mu \mathrm{m}$ $(h v=1 \mathrm{eV})$, затем наблюдается резкий рост, который достигает своего максимального значения при $\lambda=1.09 \mu \mathrm{m}$ $(h v=1.14 \mathrm{eV})$, при $h v>1.14 \mathrm{eV}$ чувствительность фотоэлементов, легированных никелем, также падает достаточно резко до $h v=1.35 \mathrm{eV}$.

Полученные результаты трудно объяснить поглощением электроактивными изолированными атомами никеля в исследуемой области спектра, так как их концентрация достаточно низкая $\left(N \sim 10^{14} \mathrm{~cm}^{-3}\right)$. Поэтому мы предполагаем, что расширение спектра ИК-поглощения может быть связано с кластерами атомов никеля, находящимися в приповерхностных областях фотоэлементов в достаточно высокой концентрации.

Один из возможных вариантов влияния кластеров заключается в увеличении коэффициента поглощения „кластерных“ областей ФЭ в инфракрасной области спектра за счет возникновения плазмонного резонанса в кластерах никеля, что приводит к лучшему совмещению области поглощения ИК-света с $p-n$-переходом. Размеры кластеров зависят от концентрации дефектов решетки кремния, степени пресыщения и условий термообработки, поэтому можно получить кластеры никеля со значительным разбросом размеров. Частота плазмонного резонанса в них будет разной, что значительно расширяет область спектральной чувствительности.

Не исключена также вероятность действия кластеров никеля как своеобразных приемных антенн инфракрасного диапазона волн. В этом случае происходит локальное увеличение амплитуды электрического поля световой частоты вблизи краев кластера, что может вызвать как непосредственно эмиссию электронов из кластера в полупроводник, так и уменьшение ширины запрещенной зоны за счет эффекта Франца-Келдыша.

Улучшение чувствительности в области спектра $h v>E_{g}$ видимо объясняется уменьшением поверхностной и (или) объемной рекомбинации за счет легирования никелем. Кластеры атомов никеля, которых на поверхности значительно больше, чем в объеме, обладают сильными геттерирующими и возможно, пассивирующими [19] свойствами, что уменьшает рекомбинацию неосновных носителей заряда и соответственно приводит к увеличению коэффициента собирания фотоэлемента.

\section{5. Возможность легирования никелем до формирования $\boldsymbol{p}-\boldsymbol{n}$-перехода ФЭ}

Вышеприведенные результаты получены в случае, когда обогащенная никелем область в кремниевых ФЭ создавалась после формирования $p-n$-перехода. Однако, с точки зрения технологии, это неудобно. Поэтому представляет интерес возможность формирования обогащенного никелем слоя до создания $p-n$-перехода $Ф Э$. 
Таблица 3. Средние значения параметров ФЭ, полученных при разных температурах диффузии никеля

\begin{tabular}{c|c|c|c|c|c|c}
\hline Диффузия никеля & \multicolumn{2}{|c|}{$T_{d i f f}=1200^{\circ} \mathrm{C}, t=3 \mathrm{~min}$} & \multicolumn{2}{|c|}{$T_{\text {diff }}=1000^{\circ} \mathrm{C}, t=10 \mathrm{~min}$} & \multicolumn{2}{|c}{$T_{d i f f}=800^{\circ} \mathrm{C}, t=30 \mathrm{~min}$} \\
\hline Тип & $\begin{array}{c}\text { После создания } \\
p-n \text {-перехода }\end{array}$ & $\begin{array}{c}\text { До создания } \\
p-n \text {-перехода }\end{array}$ & $\begin{array}{c}\text { После создания } \\
p-n \text {-перехода }\end{array}$ & $\begin{array}{c}\text { До создания } \\
p-n \text {-перехода }\end{array}$ & $\begin{array}{c}\text { После создания } \\
p-n \text {-перехода }\end{array}$ & $\begin{array}{c}\text { До создания } \\
p-n \text {-перехода }\end{array}$ \\
\hline$J_{s c}, \mathrm{~mA} / \mathrm{cm}^{2}$ & 28 & 33 & 32.8 & 36 & 37.5 & 38.5 \\
$V_{o c}, \mathrm{mV}$ & 570 & 590 & 585 & 590 & 600 & 605 \\
$\xi$ & 0.705 & 0.69 & 0.692 & 0.68 & 0.68 & 0.67 \\
$P_{\max }, \mathrm{mW} / \mathrm{cm}^{2}$ & 11.25 & 13.43 & 13.278 & 14.443 & 15.30 & 15.61
\end{tabular}

В качестве исходного материала использовались кремниевые пластины $p$-типа толщиной $380 \mu \mathrm{m}$ с удельным сопротивлением $0.5 \Omega \mathrm{cm}$.

На поверхность кремниевых пластин в вакууме напылялся тонкий металлический слой чистого никеля толщиной $1 \mu \mathrm{m}$, и проводилась диффузия никеля при температурах $T=1200,1000$ и $800^{\circ} \mathrm{C}$, в течение $t=3,10$ и $30 \mathrm{~min}$ соответственно. Затем создавался $p-n$-переход диффузией фосфора в „никелевую“ сторону пластины при $T=1000^{\circ} \mathrm{C}$ в течение $t=0.5 \mathrm{~h}$, при этом глубина $p-n$-перехода составляла $0.5-0.75 \mu \mathrm{m}$. После диффузии проводился дополнительный термоотжиг при $T=800^{\circ} \mathrm{C}$ в течение $t=0.5 \mathrm{~h}$. После создания никелевых омических контактов были измерены ВАХ ФЭ и определены параметры $U_{o c}$ и $J_{s c}$. В табл. 3 представлены основные параметры полученных фотоэлементов.

Как видно из табл. 3, технология легирования никелем до формирования $p-n$-перехода дополнительно улучшает параметры фотоэлементов независимо от температуры диффузии никеля. Введение этапа легирования никелем до формирования $p-n$-перехода практически не усложняет технологию изготовления ФЭ, но повышает эффективность.

\section{6. Влияние „объемного“ и „поверхностного“ никеля}

Как показано выше, при диффузии никеля распределение атомов имеет особый характер - высокая и быстро спадающая концентрация на поверхности, и сравнительно постоянная в объеме. Поэтому можно выявить относительный вклад „поверхностных“ и „объемных“ атомов никеля, если удалить поверхностный, сильнолегированный никелем слой.

Образцы ФЭ изготавливались по вышеприведенной технологии, диффузия никеля проводилась до формирования $p-n$-перехода. После диффузии никеля с поверхности образцов сошлифовали порядка $2.5-3 \mu \mathrm{m}$, чтобы убрать обогащенный никелем слой в приповерхностной области. При этом равновесная „объемная“ концентрация никеля соответствовала растворимости никеля при температуре диффузии, и составила $10^{16}-10^{17} \mathrm{~cm}^{-3}$.

Как показали результаты экспериментов, заметного эффекта улучшения параметров ФЭ при этом не наблю- далось. Поэтому мы можем однозначно утверждать, что улучшение параметров ФЭ в основном связано со свойствами поверхностного слоя, в котором концентрация никеля достигает $n_{s} \sim 10^{20}-10^{21} \mathrm{~cm}^{-3}$.

Для использования полученных результатов при производстве кремниевых ФЭ предлагается проводить диффузию никеля из химически осажденного на поверхность кремния слоя [20]. Это позволяет непосредственно использовать разработанную технологию улучшения параметров $Ф Э$ в промышленном производстве кремниевых фотоэлементов.

\section{Заключение}

Таким образом, можно сделать следующие выводы.

1. Максимальная концентрация никеля в приповерхностном обогащенном слое слабо зависит от температуры диффузии и при последующих термообработках с температурой ниже $900^{\circ} \mathrm{C}$ обогащенный слой сохраняется.

2. Оптимальные условия диффузии никеля в кремний $-T_{\text {diff }}=800-850^{\circ} \mathrm{C}, t=30 \mathrm{~min}$.

3. Положительный эффект влияния легирования никелем кремниевого фотоэлемента сравнительно слабо зависит от глубины $p-n$-перехода.

4. Наблюдался существенный рост величины $J_{s c}$ для $\Phi Э$, легированных никелем, практически во всей исследованной области спектра.

5. Легирование никелем кремния до формирования $p-n$-перехода является более эффективной и простой технологией.

Если использовать стандартное просветляющее покрытие и омические контакты, имеющие оптимальную форму, то параметры фотоэлементов на основе предлагаемой технологии могут быть улучшены на 15-20\%. Это означает, что предложенное решение позволяет без существенных изменений технологического процесса и с малым затратами создавать более эффективные фотоэлементы.

\section{Благодарности}

Авторы выражает благодарность старшему преподавателю С.В. Ковешникову за участие в обсуждении результатов. 


\section{Финансирование работы}

Работа выполнена в рамках проекта ОТ-Ф2-50 „Разработка научных основ формирования элементарных ячеек $\mathrm{A}^{\mathrm{II}} \mathrm{B}^{\mathrm{VI}}$ и $\mathrm{A}^{\mathrm{III}} \mathrm{B}^{\mathrm{V}}$ в решетке кремния - новый подход в получении перспективных материалов для фотоэнергетики и фотоники“.

\section{Конфликт интересов}

Авторы заявляют, что у них нет конфликта интересов.

\section{Список литературы}

[1] М.К. Бахадырханов, С.Б. Исамов, 3.Т. Кенжаев, С.В. Ковешников. Письма в ЖТФ, 45(19), 3 (2019). [M.K. Bakhadyrkhanov, S.B. Isamov, Z.T. Kenzhaev, S.V. Koveshnikov. Tech. Phys. Lett., 45(10), 959 (2019). DOI: $10.1134 / \mathrm{S} 1063785019100031]$

[2] M.K. Bakhadyrkhanov, S.B. Isamov, Z.T. Kenzhaev, D. Melebaev, Kh.F. Zikrillayev, G.A. Ikhtiyarova. Appl. Solar Energy., 56 (1), 13 (2020). DOI: $10.3103 / \mathrm{S} 0003701 \mathrm{X} 2001003 \mathrm{X}$

[3] J. Lindroos, D.P. Fenning, D.J. Backlund, E. Verlage, A. Gorgulla, S.K. Estreicher, H. Savin, T. Buonassisi. J. Appl. Phys., 113, 204906 (2013). DOI: 10.1063/1.4807799

[4] F.H.M. Spit, D. Gupta, K.N. Tu. Phys. Rev. B, 39 (2), 1255 (1989). DOI: 10.1103/PhysRevB.39.1255

[5] M.K. Bahadirkhanov, B.K. Ismaylov, K.A. Ismailov, N.F. Zikrillaev, S.B. Isamov. Intern. J. Adv. Sci. Technol., $29(9 \mathrm{~s}), 6308$ (2020).

[6] V.L. Mazalova, O.V. Farberovich, A.V. Soldatov. J. Phys.: Conf. Series, 640, 012025 (2015). DOI:10.1088/1742-6596/640/1/012025

[7] М.К. Бахадирханов, Б.К. Исмайлов. Приборы, 6 (240), 44 (2020).

[8] А.С. Астащенков, Д.И. Бринкевич, В.В. Петров. Доклады БГУИР, 8 (38), 37 (2018).

[9] D.J. Backlund, S.K. Estreicher. Phys. Rev. B, 81, 235213 (2010). DOI: 10.1103/PhysRevB.81.235213

[10] D.J. Fisher. Diffusion in Silicon 10 Years of Research (Scitec publications, 2010)

[11] Б.И. Болтакс. Диффузия и точечные дефбекты в полупроводниках (Наука, Л., 1972)

[12] Е.П. Неустроев, С.А. Смагулова, И.В. Антонова, Л.Н. Сафронов. ФТП, 38 (7), 791 (2004). [Е.P. Neustroev, S.A. Smagulova, I.V. Antonova, L.N. Safronov. Semiconductors, 38 (7), 758 (2004). DOI: $10.1134 / 1.1777595]$

[13] В.И. Орлов, Н.А. Ярыкин, Е.Б. Якимов. ФТП, 53 (4), 433 (2019). [V.I. Orlov, N.A. Yarykin, E.B. Yakimov. Semiconductors, 53 (4), 411 (2019). DOI: $10.21883 /$ FTP.2019.04.47672.9020]

[14] И.Б. Чистохин, К.Б. Фрицлер. Письма в ЖТФ, 46 (21), 11 (2020). DOI: 10.21883/PJTF.2020.21.50188.18455

[15] V.V. Hung, P.T.T. Hong, B.V. Khue. Proc. Natl. Conf. Theor. Phys., 35, 73 (2010).

[16] И.Е. Панайотти, Е.И. Теруков, И.С. Шахрай. Письма в ЖТФ, 46 (17), 3 (2020).

DOI: $10.21883 /$ PJTF.2020.17.49883.18377
[17] M.A. Green, Y. Hishikawa, W. Wart, et al. (version 54), Prog Photovolt Res Appl., 27, 565 (2019). https://doi.org/10.1002/pip.3171

[18] Б.И. Фукс. ФТП, 48 (12), 1704 (2014).

[19] А.Г. Рябухин, Е.Г. Новоселова, И.И. Самарин. Вестник ЮУрГУ, 10, 34 (2005).

[20] A.A. Istratov, P. Zhang, R.J. McDonald, A.R. Smith, M. Seacrist, J. Moreland, J. Shen, R. Wahlich, E.R. Weber. J. Appl. Phys., 97 (02), 023505 (2005). DOI: 10.1063/1.1836852 